\title{
Evaluation of a Novel Shallow Aggregate Ebb- and-flood Culture System and Transplant Size Effects on Hydroponic Basil Yield
}

\author{
Samuel Doty ${ }^{1}$, Ryan W. Dickson ${ }^{2}$, and Michael Evans ${ }^{3}$
}

deep flow technique, nutrient film technique, Ocimum basilicum, soilless culture

SUMMARY. Ornamental bedding plant operations transitioning to leafy greens and herb production must decide whether to invest in new hydroponic equipment or modify existing culture systems for edible crops. In addition, common practices used to increase space-use and production efficiencies during bedding plant production may be modified for hydroponic leafy greens and herbs, such as purchasing large seedlings for transplant. The objective of the first experiment was to evaluate plant growth in a modified and novel shallow aggregate ebb-and-flood (SAEF) system intended for bedding plant growers with an emphasis on comparing yield across four basil (Ocimum basilicum) cultivars grown in the SAEF system to those grown using the traditional nutrient film technique (NFT) and deep water culture (DWC) hydroponic systems. The second experiment objective was to evaluate basil seedling size and the time of transplant to NFT hydroponic systems to determine effects on the final yield. 'Genovese' basil seedlings were grown in trays with cell counts of 32, 50, 72 , 105 , and 162 cells with corresponding root volumes per plant of 98.1, 50.2, 38.5, 19.6 , and $16.3 \mathrm{~cm}^{3}$, respectively. Seedlings were transplanted to NFT systems at 14 , 21 , and 28 days after sowing and were harvested at 35 days. In the first experiment, overall basil shoot fresh and dry weights per plant were intermediate in the SAEF system (90.4 and 8.3 g) compared with the DWC (102.6 and 9.1 g) and NFT (75.8 and $6.6 \mathrm{~g}$ ) hydroponic systems. In the second experiment, final shoot fresh and dry weight per plant increased as seedling root volume increased from $16.3 \mathrm{~cm}^{3}[72.8$ and $5.5 \mathrm{~g}$ (162-cell tray)] to $98.1 \mathrm{~cm}^{3}$ [148.5 and $12.2 \mathrm{~g}$ (32-cell tray)]. Transplanting seedlings at later dates decreased yield across tray size and root volume treatments. Differences in yield between culture systems may have resulted from differences in nutrient supply and availability for plant uptake. Transplant of large seedling plugs to hydroponic culture was not shown to increase space-use efficiency after transplant without compromising yield, likely because root zone factors limited growth during seedling production. Further investigation into maximizing plant growth during seedling production and evaluating the effects of seedling size and transplant practices are needed to determine the potential for increasing space-use and production efficiencies.

Received for publication 24 Apr. 2020. Accepted for publication 31 July 2020.

Published online 27 August 2020

${ }^{1}$ Department of Biology, UT Valley University, Orem, UT 84058

${ }^{2}$ Department of Horticulture, University of Arkansas, Fayetteville, AR 72701

${ }^{3}$ School of Plant and Environmental Sciences, Virginia Tech University, Blacksburg, VA 24061

We thank the University of Arkansas Department of Horticulture and Arkansas Division of Agriculture for supporting for this research. We also thank Kevin Thompson of the University of Arkansas Agricultural Statistics Department for statistical advice and consulting.

The use of trade names in this publication does not imply endorsement of the products named or criticism of similar ones not mentioned.

R.W.D. is the corresponding author. E-mail: ryand@ uark.edu.

This is an open access article distributed under the CC BY-NC-ND license (https://creativecommons.org/ licenses/by-nc-nd $/ 4.0 /$ ).

https://doi.org/10.21273/HORTTECH04635-20
$\mathrm{O}$ rnamental bedding plant operations in the United States are continually transitioning to the production of edible crops (Chidiac, 2017), particularly highvalue leafy greens and herbs. However, culture systems used to produce edible and ornamental crops tend to differ in system design and nutrient and water delivery. Fresh market basil (Ocimum basilicum), for example, is typically produced in hydroponic systems in which plant roots are submerged in nutrient solution to promote maximum growth and yield (Gómez et al., 2019; Resh, 2012). Bedding plants are often produced in soilless substrate and containers and periodically irrigated with a fertilizer solution using drip emitters or ebband-flood irrigation (Lieth and Oki, 2008). An important decision for bedding plant growers transitioning to edible crop production is whether to invest in new hydroponic equipment or modify existing culture systems (Chidiac, 2017).

Nutrient film technique (NFT) and deep water culture (DWC) are common hydroponic systems used commercially for the production of leafy greens and herbs (Gómez et al., 2019; Resh, 2012; Walters and Currey, 2015a; Wolf et al., 2005). The NFT systems contain plants within narrow gutters or troughs, where root systems are exposed to a continually flowing thin film of nutrient solution. Alternatively, DWC systems expose plant roots to a relatively large volume of nutrient solution, typically ranging from 6 to 8 inches in depth, where roots are completely submerged in nutrient solution. With both systems, commercial producers maintain strict control over solution $\mathrm{pH}$, nutrient concentrations, oxygen levels, and pathogens to ensure optimal plant growth and yield (Currey, 2017; Resh, 2012). The NFT systems are popular among bedding plant growers transitioning to leafy greens and herb production, partially because NFT systems are relatively low-cost and troughs are at a comfortable working level for employees (Walters and Currey, 2015b).

Chidiac (2017) designed a novel soilless substrate system-a shallow 
aggregate ebb-and-flood (SAEF) system-for bedding plant growers transitioning to edible crop production. The SAEF system consists of modifying traditional ebb-and-flood irrigation systems by adding a layer of clay aggregate substrate to the bottom of the flood table. Seedlings are transplanted and grown directly in the substrate, which is periodically subirrigated with nutrient solution, similar to ebb-and-flood irrigation with container crop production. The SAEF system is intended to allow bedding plant growers to easily modify ebb-and-flood systems for food crop production without having to purchase NFT and DWC systems (Chidiac, 2017). However, the viability of modifying an ebb-and-flow system in this manner for edible crops needs to be evaluated by comparing plant growth and yield of SAEF systems to those of traditional NFT and DWC hydroponics.

Bedding plant growers sometimes purchase and transplant large seedling plugs to finishing containers as a strategy to improve production and space-use efficiencies (Fisher et al., 2006). A similar strategy may also apply to edible crop seedlings transplanted to hydroponic systems. For bedding plants, large seedlings finish rapidly after being transplanted to containers because plants are developmentally mature, thus reducing the time between transplant and a finished crop and allowing for additional crop cycles (Fisher et al., 2006). However, large seedlings require additional time for adequate root and shoot growth during propagation, as well as trays with larger root volumes to avoid issues with root restriction and excessive drying of the root zone (Fisher et al., 2006; Latimer, 1991; van Iersel, 1997). There is a need to investigate the potential of transplanting large seedling plugs to hydroponic systems to reduce the time between transplant and harvest without compromising yield.

The objective of the first experiment was to evaluate edible crop growth in a novel SAEF culture system using basil as a model crop, with an emphasis on comparing basil growth and morphology to plants produced in traditional NFT and DWC hydroponic systems. We hypothesized that basil yield would be lower in the SAEF system compared with DWC, based on previous research comparing plant growth of hydroponic and substrate cultures (Blok et al., 2017). The objective of the second experiment was to evaluate the effect of seedling size and the time of transplant to NFT hydroponic systems on final yield. Large seedlings of bedding plants are typically grown in trays with relatively low cell counts and large root volumes to avoid root restriction (Fisher et al., 2006); therefore, seedling size in this study is discussed in terms of tray cell count and root volume. We hypothesized that basil seedlings grown in the largest root volume would have the greatest yield as a result of decreased restriction of root growth.

\section{Materials and methods}

\section{Expt. 1: Basil growth in a novel SAEF system compared with DWC and NFT hydroponic systems}

Experimental Design. The experiment was a split-plot factorial with culture system (NFT, DWC, and SAEF systems) as the whole plot factor and basil cultivars (Genovese, Mrs. Burns Lemon, Cinnamon, and Sweet Thai) as the split-plot factor, with three replications per culture system-cultivar treatment combination. Replication was achieved by conducting three separate experimental runs; each experimental run served as one replication and contained all hydroponic systems and cultivars. System locations were rerandomized between experimental runs. Placement of cultivar groups was randomized within each system for each replication. Each experimental run started with the transfer of basil seedlings to the different culture systems, which occurred on 19 May 2017, 14 Aug. 2017, and 1 Jan. 2018.

The experiment was conducted in a controlled environment (glassglazed) greenhouse at the University of Arkansas in Fayetteville (lat. $36.0764^{\circ} \mathrm{N}$, long. $\left.94.1608^{\circ} \mathrm{W}\right)$. Greenhouse heating and cooling set points were 23 and $27^{\circ} \mathrm{C}$, respectively. All plants in the experiment were grown under ambient light and photoperiod conditions. The outside daily light integral for the three experimental runs were (mean \pm SD) $40.0 \pm 12.3$ (19 May 2017), $35.1 \pm 7.9$ (14 Aug. 2017), and $12.9 \pm 6.5$ (1 Jan. 2018) $\mathrm{mol} \cdot \mathrm{m}^{-2} \cdot \mathrm{d}^{-1}$ of photosynthetically active radiation, and the outside average daily temperatures were $21.5 \pm 3.5$, $22.4 \pm 3.0$, and $1.6 \pm 7.6{ }^{\circ} \mathrm{C}$, respectively; these temperatures were measured using a weather station (WatchDog 2900ET; Spectrum Technologies, Aurora, IL).

Nutrient solution. The hydroponic nutrient solution was the same across all three systems and consisted of (in $\mathrm{mg} \cdot \mathrm{L}^{-1}$ ) 195.1 nitrogen $(\mathrm{N}), 34.1$ phosphorus $(\mathrm{P}), 267.2$ potassium $(\mathrm{K}), 171.0$ calcium $(\mathrm{Ca})$, 60.6 magnesium $(\mathrm{Mg}), 75.8$ sulfur (S), 4.5 iron $(\mathrm{Fe}), 1.0$ manganese (Mn), 0.5 boron (B), 0.1 copper $(\mathrm{Cu})$, and 0.1 zinc $(\mathrm{Zn})$ formulated using commercial-grade calcium nitrate, potassium nitrate, potassium sulfate, monopotassium phosphate, magnesium sulfate heptahydrate, iron-diethylenetriaminepentaacetic acid [DTPA (11\%)], manganese sulfate monohydrate, zinc sulfate heptahydrate, boric acid, copper sulfate pentahydrate, and ammonium molybdate tetrahydrate mixed in tap water. Solution electrical conductivity (EC) and $\mathrm{pH}$ were monitored in each system and maintained at $1.4 \pm 0.05 \mathrm{mS} \cdot \mathrm{cm}^{-1}$ and $5.9 \pm 0.2$, respectively, by daily adjustments to the fertilizer concentration in the replenishment solution (same as the starting hydroponic nutrient solution) and additions of $0.1 \mathrm{~N}$ sulfuric acid $\left(\mathrm{H}_{2} \mathrm{SO}_{4}\right)$.

Plant culture. Untreated seed for each cultivar (Johnny's Selected Seeds, Waterville, ME) were sown in 162-cell rockwool sheets $(\mathrm{A} / \mathrm{O}$ sheets; Grodan, Roermond, The Netherlands) as three seeds per cell and germinated on a greenhouse bench. During germination and early plant growth, rockwool sheets were subirrigated for 2 min every hour using the same nutrient solution described previously. Basil seedlings were transplanted to hydroponic systems $14 \mathrm{~d}$ after sowing, when all plants had at least two true leaves.

Hydroponic systems. The NFT system consisted of 12 separate $150 \times$ $10 \times 5$-cm polypropylene hollow gutters (AM Hydro, Arcata, CA) positioned on a $2.5 \%$ slope across the top of the greenhouse bench. Plants were transferred to 2-inch-diameter holes drilled in the top of each gutter so that the rockwool cube and root system were located within the gutter interior. Hydroponic nutrient 
solution was continually pumped from a reservoir tank below the bench and into each gutter at $1.26 \mathrm{~L} \cdot \mathrm{min}^{-1}$, where the nutrient solution flowed over plant roots before draining back into the reservoir. The nutrient solution depth in each system was $\approx 1 \mathrm{~mm}$. Each gutter held eight basil plants, and individual plant spacing between and within gutters was maintained at $20 \mathrm{~cm}$. Three gutters were used for each cultivar for a total of 24 basil plants per cultivar $(3$ gutters $\times 8$ plants per gutter $=24$ total plants per cultivar), and gutters containing the same cultivar were adjacent.

The DWC system consisted of two separate polypropylene tanks measuring $90 \times 175 \times 15-\mathrm{cm}$ (Botanicare, Chandler, AZ) positioned on top of two adjacent greenhouse benches and filled with hydroponic nutrient solution. Each tank held a 90 $\times 175 \times 5-\mathrm{cm}$ polystyrene foam board (Dow, Midland, MI) that floated on the surface of the nutrient solution contained within each tank. Basil transplants were transferred to 2inch-diameter net cups (one transplant per cup) that fit into holes drilled in the polystyrene foam board. Roots were submerged and allowed to grow in the nutrient solution, which was continually aerated using electric air pumps (Tetra Whisper Air Pump 10-30 gal; Spectrum Brands Pet, Blacksburg, VA). The DWC system held a total of 80 plants (40 plants per tank), and plants were arranged in 16 rows with 5 plants per row. Each cultivar occupied four adjacent rows ( 4 rows $\times 5$ plants per row $=20$ total plants per cultivar), and plant spacing was the same as that used for the NFT system.

The SAEF systems consisted of two separate polypropylene tanks measuring $125 \times 250 \times 15 \mathrm{~cm}$ (Botanicare) positioned on top of two adjacent greenhouse benches and partially filled with expanded round clay aggregate (Mother Earth Hydroton; National Garden Wholesale Sunlight Supply, Vancouver, WA) to a depth of $3.8 \pm 0.5 \mathrm{~cm}$. Hydroponic nutrient solution was pumped from a reservoir tank below the benches and into both tanks simultaneously at $126 \mathrm{~mL} \cdot \mathrm{min}^{-1}$ for $2 \mathrm{~min}$ every $2 \mathrm{~h}$, allowing the nutrient solution to cover the roots before draining back into the reservoir. Aggregate depth and irrigation practices followed the recommendations for optimal lettuce (Lactuca sativa) yield by Chidiac (2017). The SAEF system held a total of 80 plants ( 40 plants per tank), and plants were oriented in 16 rows with five plants per row. Each cultivar occupied four adjacent rows (4 rows $\times 5$ plants per row $=20$ total plants per cultivar), and plant spacing was the same as that used for the NFT system.

Data collection. Plants were harvested $21 \mathrm{~d}$ after seedlings were transferred to the different culture systems for each experimental run. Culture systems differed in the total number of basil plants per cultivar; however, the experimental units used for data collection were identical across systems. Each experimental unit consisted of six basil plants per cultivar and culture system treatment, where harvested plants were taken from the center of each group of cultivars within each system. The extra plants surrounding those harvested for data collection served as buffer plants and were not used. Measurements across the six harvested plants per treatment were averaged and data were reported and analyzed on a per-plant basis.

The leaf chlorophyll index was measured nondestructively using a portable Soil Plant Analysis Development (SPAD) meter (Minolta Corp., Tokyo, Japan); each measurement was the average leaf chlorophyll measured across three randomly selected and fully expanded leaves per plant. The plant height and number of nodes were measured, and the average internode length was calculated by dividing the height by the number of nodes per plant.

Shoots were cut at the base of the stem and just above the rockwool surface and immediately weighed for fresh weight determination. Fresh shoot tissue was oven-dried at $70{ }^{\circ} \mathrm{C}$ for $2 \mathrm{~d}$ for dry weight determination. Total leaf area was measured before shoot tissue was oven-dried using a leaf area meter (LI-3050C; LICOR, Lincoln, NE).

Statistical anAlysis. An analysis of variance using PROC GLIMMIX (SAS version 9.4; SAS Institute, Cary, NC) was used to evaluate culture system and cultivar effects on shoot fresh weight, shoot dry weight, leaf SPAD chlorophyll content, leaf area, plant height, node number, and internode length. Mean separation was performed using Tukey's honestly significant difference (HSD) at $\alpha=0.05$.

\section{Expt. 2: Basil seedling root volume and transplant date effects on NFT hydroponics}

ExPERIMENTAL DESIGN. The experiment followed a randomized complete block design. It started on 3 May 2019, with the sowing of basil seed and a five root volume $x$ three transplant date factorial. Seedling trays differed in tray cell count and root volume per plant, with cell counts of $32,50,72,105$, and 162 cells per tray and corresponding root volumes of $98.1,50.2,38.5,19.6$, and $16.3 \mathrm{~cm}^{3}$, respectively (Table 1 ). Basil seedlings from each tray type were transplanted to NFT systems at 14,21 , and $28 \mathrm{~d}$ after sowing, when each seedling had at least two, four, or six true leaves, respectively. The experiment was conducted in a greenhouse with heating and ventilation set points of 19 and $23{ }^{\circ} \mathrm{C}$, respectively. During the experiment, the greenhouse average daily temperature was (mean $\pm \mathrm{SD}$ ) $23.3 \pm 1.3^{\circ} \mathrm{C}$ and the daily light integral was $25.6 \pm 7.2$ $\mathrm{mol} \cdot \mathrm{m}^{-2} \cdot \mathrm{d}^{-1}$ of photosynthetically active radiation; these were recorded

Table 1. Characteristics of tray types used for seedling transplant production of basil in Expt. 2. Tray cell count refers to the number of cells and plants per tray. Cell diameter, cell height, and cell volume refer to the cylindrical paper-wrapped substrate contained within each tray cell.

\begin{tabular}{lccc}
\hline Tray cell count $(\mathbf{n o} . / \text { tray })^{\mathbf{z}}$ & Cell diam $(\mathrm{cm})^{\mathbf{y}}$ & Cell ht $(\mathrm{cm})$ & Cell vol $\left(\mathrm{cm}^{3}\right)^{\mathrm{y}}$ \\
\hline 162 & 2.2 & 4.5 & 16.3 \\
105 & 2.5 & 4.0 & 19.6 \\
72 & 3.5 & 4.0 & 38.5 \\
50 & 4.0 & 4.0 & 50.2 \\
32 & 5.0 & 5.0 & 98.1 \\
\hline
\end{tabular}

${ }^{\mathrm{z}}$ Tray count values indicate the number of cells per standard $1.6-\mathrm{ft}^{2}\left(0.15-\mathrm{m}^{2}\right)$ tray area.

${ }^{\mathrm{y}} 1 \mathrm{~cm}=0.3937$ inch; $1 \mathrm{~cm}^{3}=0.0610$ inch $^{3}$. 
Table 2. Cultivar and system main and interaction effects on total shoot fresh weight, total shoot dry weight, leaf Soil Plant Analysis Development (SPAD) chlorophyll content, total leaf area, average plant height, average node number, and average internode length for basil after $21 \mathrm{~d}$ in the first experiment. Culture systems included deep water culture (DWC) hydroponics, nutrient film technique (NFT) hydroponics, and shallow aggregate ebb-and-flood (SAEF) soilless system.

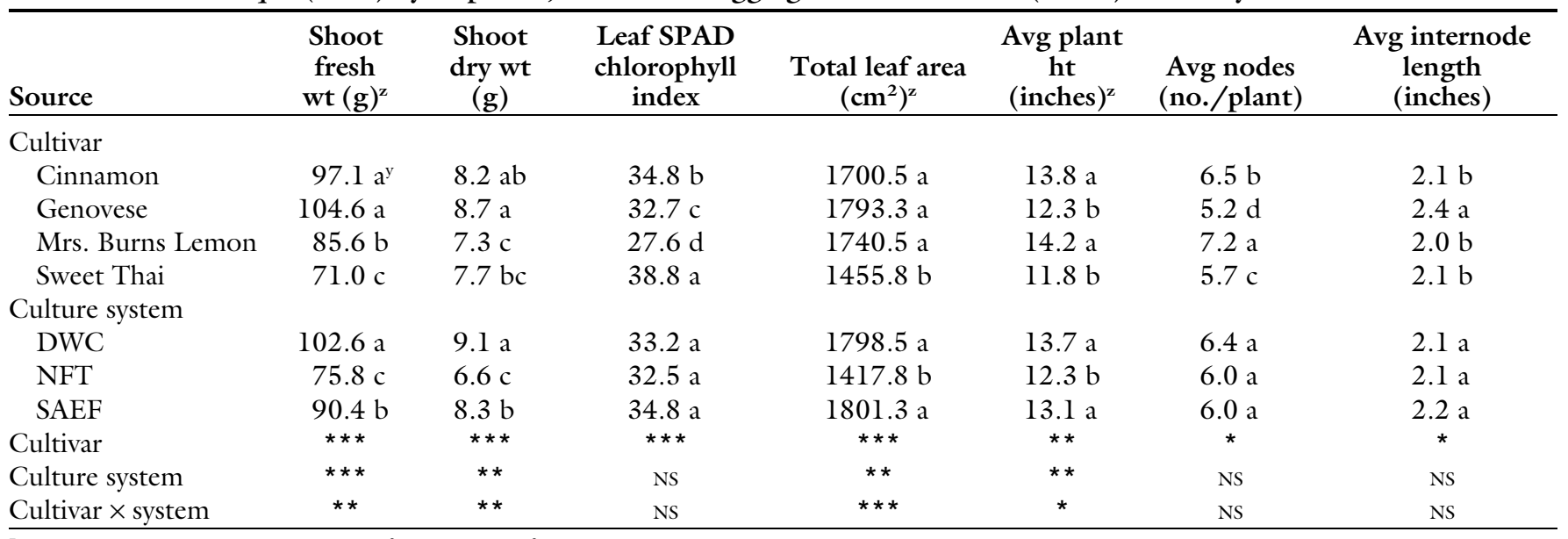

${ }^{\mathrm{z}} 1$ inch $=2.54 \mathrm{~cm} ; 1 \mathrm{~g}=0.0353 \mathrm{oz} ; 1 \mathrm{~cm}^{2}=0.1550$ inch $^{2}$.

${ }^{y}$ Data represent least-square means of 3 and 12 replicates for culture system and cultivar, respectively. Mean separation was performed using Tukey's honestly significant difference with $\alpha=0.05$.

NS, ${ }^{*},{ }^{*},{ }^{* *}$ Nonsignificant or significant at $P \leq 0.05,0.01$, or 0.0001 , respectively.

using an environmental control system (GEMLink 5; QCom, Temecula, CA).

Replication was achieved during seedling production and after transplant to hydroponic NFT systems using a randomized complete block design with three replications per treatment. Seeds were sown in three trays per tray cell count and root volume; each individual tray served as one replicate $(n=3)$. At each transplant date, two plants were taken from the center of each replicate tray and transferred to three NFT systems positioned adjacent to each other on a greenhouse bench. Seedlings taken from the same replicate tray were transferred to the same NFT system, where the three NFT systems each served as a replication $(n=3)$. At each transplant date, plant positions in each gutter were randomly assigned. In addition, all gutters per NFT system were re-randomized at the second and third transplant dates (21 and 28 d, respectively). Extra plants not used for experimentation were placed at the front and back of each gutter, as well as in additional gutters along the sides of each system, as a buffer.

Plant culture. Seedling trays contained cells with a cylindrical paper-wrapped and peat-based soilless substrate (Ellepots; Elleguard, Storstrømsvej, Denmark), and seeds of 'Genovese' basil (Johnny's Selected Seeds) were sown as one seed per cell. Seeded trays were subirrigated as needed using a commercial water-soluble nutrient formulation (16.0N-1.7P-14.9K Jack's Oasis Hydro FeED; JR Peters, Allentown $\mathrm{PA}$ ) mixed at $200 \mathrm{mg} \cdot \mathrm{L}^{-1}$ nitrogen in tap water. Applied nutrient solution EC and $\mathrm{pH}$ were $1.3 \mathrm{mS} \cdot \mathrm{cm}^{-1}$ and 5.9 , respectively.

The nutrient solution used in the NFT systems was identical to that of Expt. 1. Solution $\mathrm{pH}$ and EC were maintained within target ranges of 5.5 to 6.5 and 1.5 to $2.0 \mathrm{mS} \cdot \mathrm{cm}^{-1}$, respectively, by daily adjustments to the fertilizer concentration in the replenishment solution and additions of $0.1 \mathrm{~N}$ sulfuric acid $\left(\mathrm{H}_{2} \mathrm{SO}_{4}\right)$. In addition, nutrient solutions for each NFT system were fully replaced each week.

Each NFT system contained 12 separate $150 \times 40 \times 4$-cm polypropylene gutters (AM Hydro) positioned on a $2.5 \%$ slope across the top of the greenhouse bench. The top of each gutter was removed and replaced with 6-mil white-black horticultural plastic film with the white side facing upward. Substrate for each transplant was pushed through perpendicularly cut slits in the plastic film. The purpose of the plastic slits was to hold the substrate in place within the gutter as well as accommodate different substrate volumes and cell diameters (Table 1). Individual plants were spaced between and within gutters at $20 \mathrm{~cm}$.

Data collection. Plants were harvested from NFT systems on 8 June 2019 (36 d after sowing seed), and data were collected and analyzed on a per plant basis for each root volume and transplant date treatment combination. Within each NFT system, the two plants per treatment served as subreplicates, and subreplicate data were averaged to provide one treatment replicate value for data analysis. Total shoot height per plant was measured just before harvest. Shoot fresh and dry weights were measured as described above.

STATISTICAL ANALYSIS. An analysis of variance using PROC GLM (SAS version 9.4) was performed to evaluate the root volume and transplant date main and interaction effects on shoot fresh weight, shoot dry weight, and plant height at harvest. Mean separation was performed using Tukey's HSD at $\alpha=0.05$.

\section{Results}

EXPT. 1: BASIL GROWTH IN A NOVEL SAEF SYSTEM COMPARED WITH DWC AND NFT HYDROPONIC systems. Shoot fresh weight and dry weight per plant at harvest differed between cultivars and culture systems $[P<0.05$ (Table 2)]. Shoot fresh 
weight was greatest for 'Genovese' and 'Cinnamon' and lowest for 'Sweet Thai'. Dry weight was greatest for 'Genovese' and lowest for 'Mrs. Burns Lemon'. Shoot fresh weight and dry weight across cultivars were consistently greatest for DWC, lowest for NFT, and intermediate for SAEF. 'Sweet Thai' basil was the only cultivar with similar fresh and dry weights in the SAEF and NFT systems (data not shown), which resulted in the interaction effect between the cultivar and system (Table 2). Mean separation for culture system-cultivar treatment combinations were not reported because shoot weight trends were similar among the remaining cultivars and the main objective of this experiment was to compare overall system effects.

Total plant height and leaf area were also influenced by cultivar and culture system $[P<0.05$ (Table 2 ) $]$. Cultivars Cinnamon and Mrs. Burns Lemon were taller than Genovese and Sweet Thai. Overall plant height was lower for cultivars grown in NFT than in DWC and SAEF systems. Leaf area was also lower in NFT than for DWC and SAEF, and it was lowest for 'Sweet Thai' compared with other cultivars. Similar to trends of shoot fresh and dry weights, plant height and leaf area for 'Sweet Thai' were similar in NFT and SAEF (data not shown), resulting in the interaction effect between cultivar and system (Table 2).

The leaf chlorophyll index differed between cultivars at harvest $(P<$ $0.0001)$, but it was not influenced by the culture system (Table 2). In this experiment, leaf SPAD chlorophyll content values greater than 30 indicated visibly green foliage. The leaf chlorophyll index was lowest for 'Mrs. Burns Lemon' (leaf chlorophyll of 27.6) (Table 2).

Node number per plant and average internode length at harvest differed between cultivars $(P<0.05)$ but were unaffected by culture system (Table 2). Although statistically significant, the numbers of nodes per plant were only slightly different between cultivars, ranging from $\mathbf{5 . 2}$ nodes for Genovese to 7.2 nodes for Cinnamon. Similarly, internode length was slightly greater for Genovese compared with Cinnamon, Mrs. Burns Lemon, and Sweet Thai (Table $2)$.
EXPT. 2: BASIL SEEDLING ROOT VOLUME AND TRANSPLANT DATE EFFECTS ON NFT HYDROPONICS. Root volume and transplant date had main effects on, but no interaction with, final shoot fresh weight, shoot dry weight, and shoot height at harvest $[P$ $<0.05$ (Figs. 1 and 2)]. Overall, shoot fresh weight was greatest for plants transferred to NFT systems at 14 $\mathrm{d}$ after sowing and lowest at $28 \mathrm{~d}$ after sowing, with $21 \mathrm{~d}$ after sowing being intermediate (Fig. 1A). Trends for shoot dry weight were similar to those observed for shoot fresh weight (Fig. 1B). Shoot dry weight at harvest was greatest, intermediate, and lowest 14 , 21 , and $28 \mathrm{~d}$ after sowing, respectively (Fig. 1B). Shoot height was greatest for the first and second transplant dates, and was lower for the third transplant date (Fig. 1C).

Root volume had main effects on shoot fresh weight $(P \leq 0.0001)$, shoot dry weight $(P \leq 0.0001)$, and shoot height $(P \leq 0.0001)$ at harvest (Fig. 2). Overall, shoot fresh weight increased as root volume increased (Fig. 2), and fresh weight was greatest for plants grown in 32-cell trays and lowest for 162-cell tray. Trends for shoot dry weight were similar to those observed for shoot fresh weight, and shoot dry weight increased as root volume increased (Fig. 2B). Shoot height at harvest was also greatest for plants grown in 32-cell trays and lowest for plants in 162-cell trays, indicating that plant height also increased as the root volume increased (Fig. 2C).

\section{Discussion}

Results indicated that basil cultivars differed in shoot growth and morphology. Overall, cultivars Genovese and Cinnamon produced greater shoot fresh weight and dry weight at harvest compared with Mrs. Burns Lemon and Sweet Thai (Table 1). Similar trends were reported by Walters and Currey (2015a) for the same cultivars grown in NFT and DWC hydroponics. Cultivars Genovese, Cinnamon, and Sweet Thai had greater leaf SPAD chlorophyll index values than Mrs. Burns Lemon in this study.

Similar to results reported by Walters and Currey (2015a), basil shoot weights were greater in DWC than in NFT hydroponic systems. Walters and Currey (2015a) found that across 35 basil cultivars, shoot dry weight was an average of $2.6 \mathrm{~g}$ greater per plant when grown in DWC compared with NFT systems, whereas shoot dry weight was $2.5 \mathrm{~g}$ greater in DWC compared with NFT in this study (Table 1 ). Other researchers have reported similar trends in culture systems with floriculture crops; for example, Blok et al. (2017) showed that growth rates for chrysanthemum (Chrysanthemum sp.) decreased $12 \%$ when grown in NFT instead of DWC. The same authors suggested that the thin film of solution with NFT supplied water and nutrients (including oxygen) at insufficient rates for chrysanthemum, thereby limiting plant growth. Roots can also develop into thick mats in NFT troughs, particularly with longterm crops, resulting in rapid depletion of nutrients in the rhizosphere that can decrease growth (Blok et al., 2017; Sonneveld and Voogt, 2009).

Nutrient solution and root zone temperature were not monitored or controlled in this study; however, it is possible that high nutrient solution and root zone temperatures reduced plant growth in NFT systems. The temperature of the nutrient solution film passing through NFT troughs can convert rapidly to the warm ambient air temperatures in greenhouses (Resh, 2012; Sonneveld and Voogt, 2009) and contribute to excessively high root zone temperatures. In contrast, large solution volumes and substrate in the DWC and SAEF systems help buffer against temperature fluctuations and reduce the potential for high root zone temperature stress (Resh, 2012).

Overall shoot weights in the SAEF system were intermediate compared with those in the commercially used DWC and NFT hydroponic systems (Table 2), suggesting that modifications of ebb-and-flood irrigation tables for edible crop production may be viable options for bedding plant operations. Reduced basil growth in the SAEF system compared with DWC may have partially resulted from an intermittent and lower supply of nutrients. The same nutrient solution was applied to each system, and plants grown hydroponically (DWC and NFT systems) received a constant supply of the entire nutrient solution volume. In contrast, plants in the SAEF system 


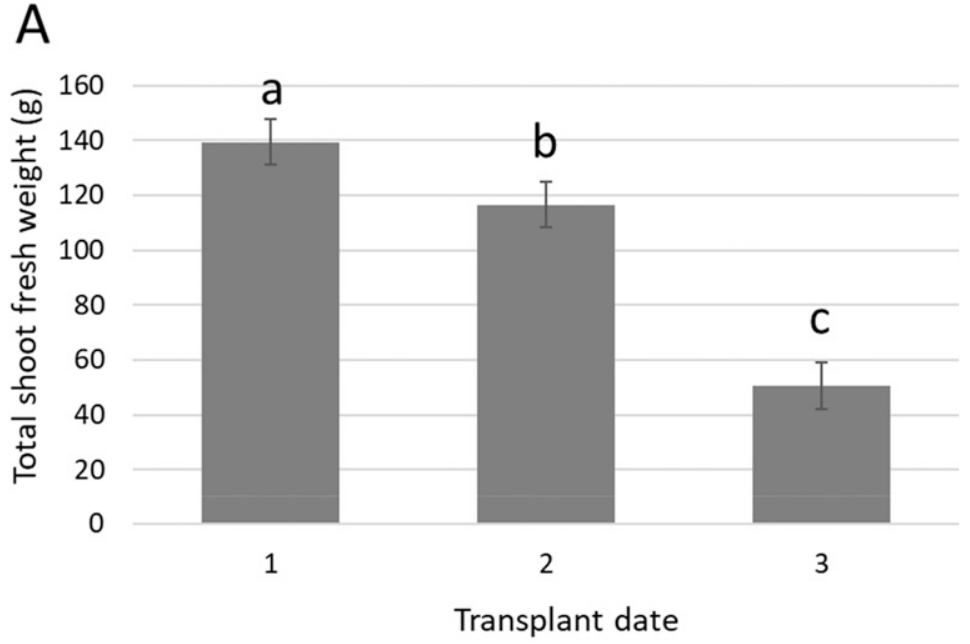

B
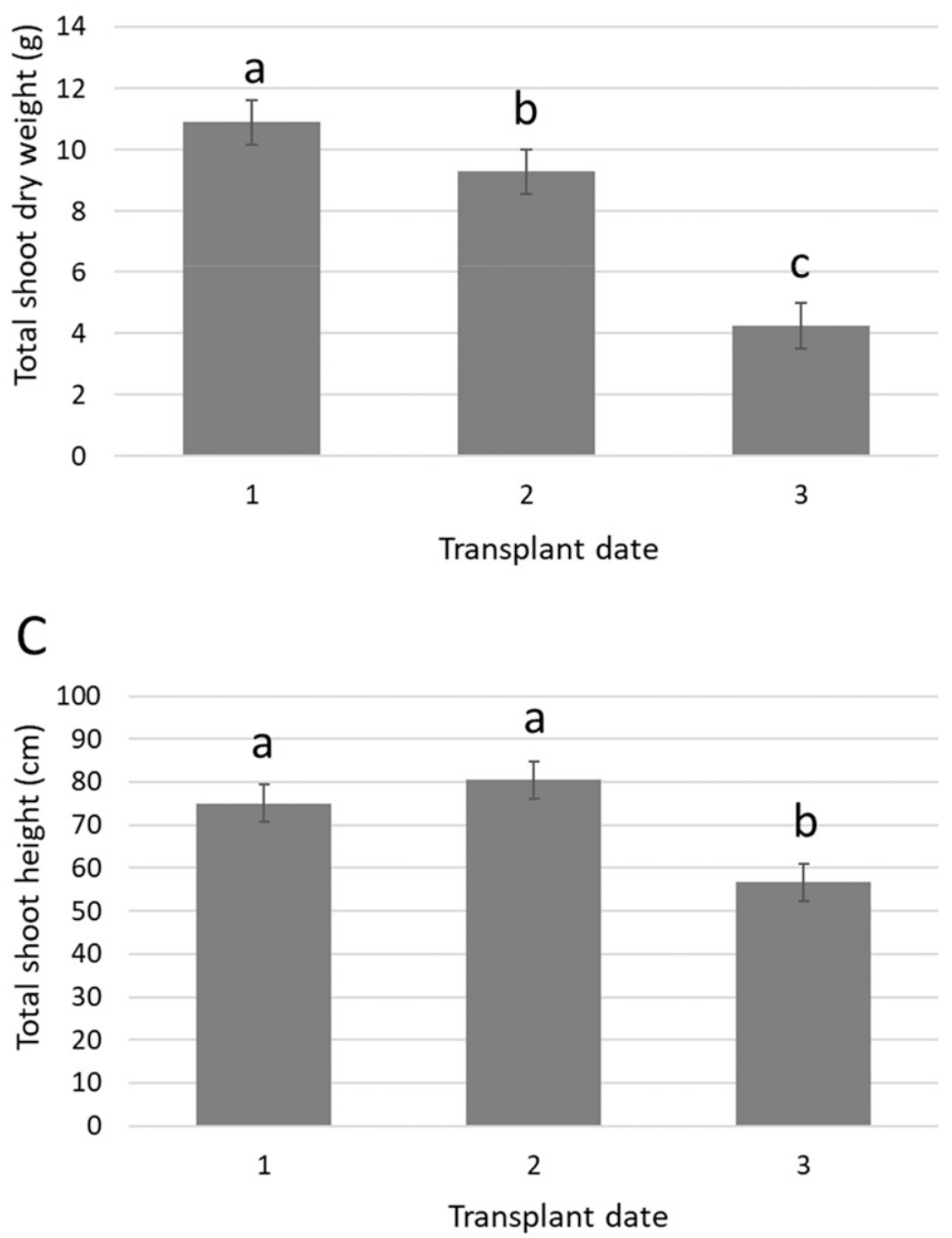

Fig. 1. Transplant date effects on basil seedling shoot fresh weight (A), shoot dry weight (B), and shoot height (C) per plant at harvest $35 \mathrm{~d}$ after sowing seeds for the second experiment. Transplant dates 1, 2, and 3 corresponded to 14, 21, and $28 \mathrm{~d}$ after sowing. Data represent least-square means of 15 replicates per treatment. Mean separation was performed using Tukey's honestly significant difference (HSD) with $\alpha=0.05$. Error bars represent $95 \%$ confidence intervals of each mean. $1 \mathrm{~g}=0.0353 \mathrm{oz} ; 1 \mathrm{~cm}=0.3937$ inch . were irrigated periodically using ebband-flood and excess nutrient solution not held by the clay aggregate drained back into the reservoir. Therefore, roots in the SAEF system were exposed only to the nutrient solution retained by the clay aggregate between irrigation events (every $2 \mathrm{~h}$ ). Incorporating substrate components with greater water-holding capacity and/or adjusting applied nutrient concentrations and fertigation frequency are strategies to increase nutrient availability and plant growth in substrate-based hydroponic systems (Bar-Yosef, 2008; Lieth and Oki, 2008).

Shoot weights decreased for basil seedlings grown with lower root volumes, particularly when transplanted late to NFT hydroponics (Fig. 1). Past research of floriculture crops has shown that low root volumes can cause root restriction and reduction in growth (Latimer, 1991; van Iersel, 1997). van Iersel (1997) found that salvia (Salvia sp.) seedlings grown in trays with $7.3-\mathrm{cm}^{3}$ root volumes suffered from root restriction and had decreased net assimilation rates compared with trays with $55^{-}, 166-$, and $510-\mathrm{cm}^{3}$ root volumes. Latimer (1991) also found that seedlings of marigold (Tagetes erecta) had $60 \%$ of the leaf area and shoot and root dry weights when grown in 7 $\mathrm{cm}^{3}$ compared with $44-\mathrm{cm}^{3}$ container volumes, and further reductions in growth occurred in the landscape after transplant. Fisher et al. (2006) showed that calibrachoa (Calibrachoa Xbybrida) young plants held for 6 to 8 weeks in 144- and 125-cell trays dried quickly, resulting in air-pruning of roots and delayed growth after transplant. In this study, basil grown in 32cell trays with the largest root volume per plant $\left(98.1 \mathrm{~cm}^{3}\right)$ still had lower shoot weights when transplanted 28 d compared with $14 \mathrm{~d}$ after sowing, but it did not exhibit the highly dense and matted root systems often characteristic of root restriction.

Root zone nutrients may have become depleted between irrigation events and limited plant growth during seedling production. Substrate EC averaged $0.46,0.42$, and 0.33 $\mathrm{mS} \cdot \mathrm{cm}^{-1}$ across tray cell count and root volume treatments when seedlings were transplanted at 14,21 , and $28 \mathrm{~d}$ after sowing, respectively (data not shown), and it was lower 


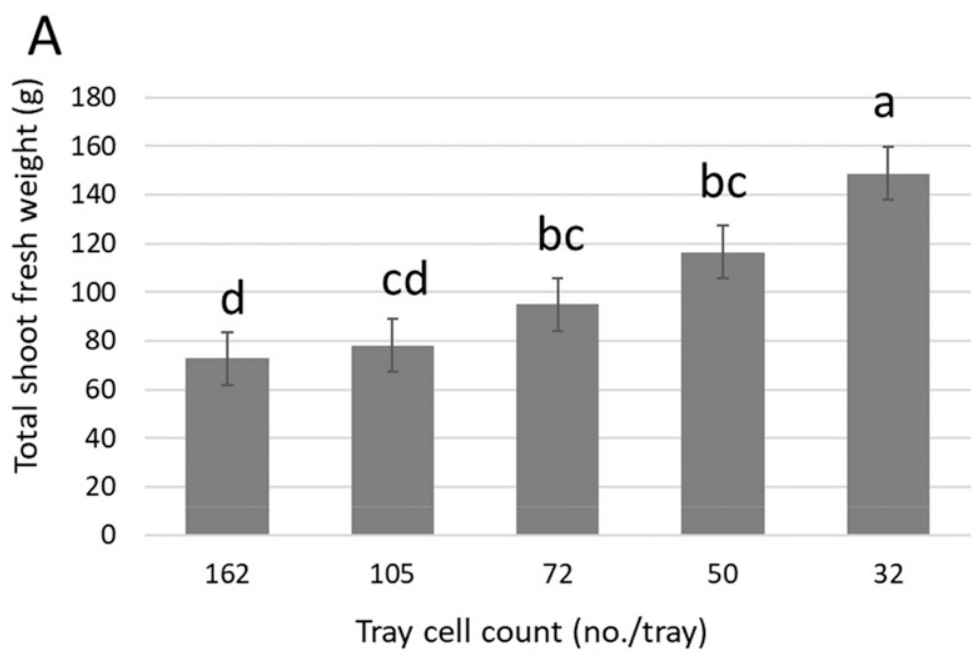

B

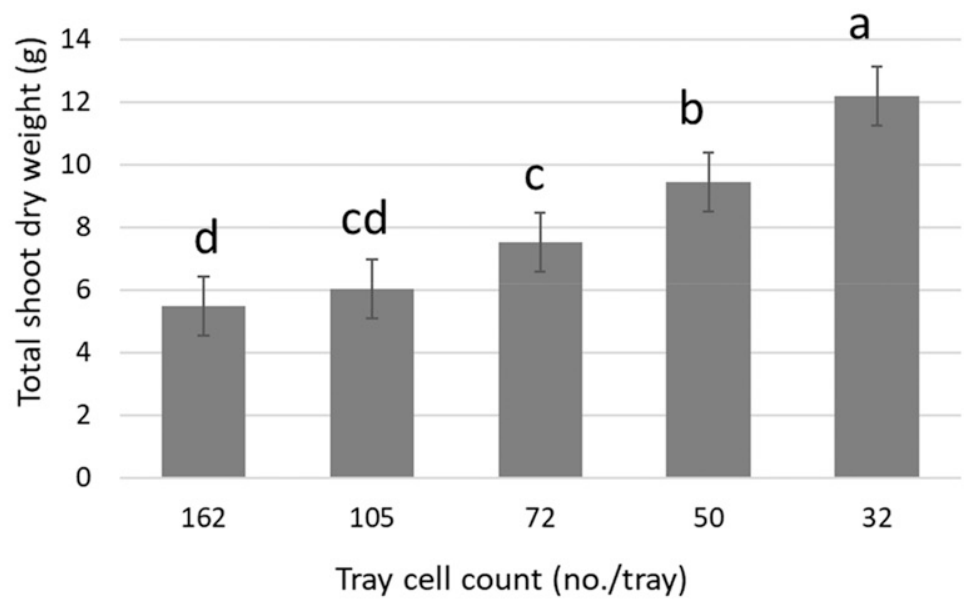

C

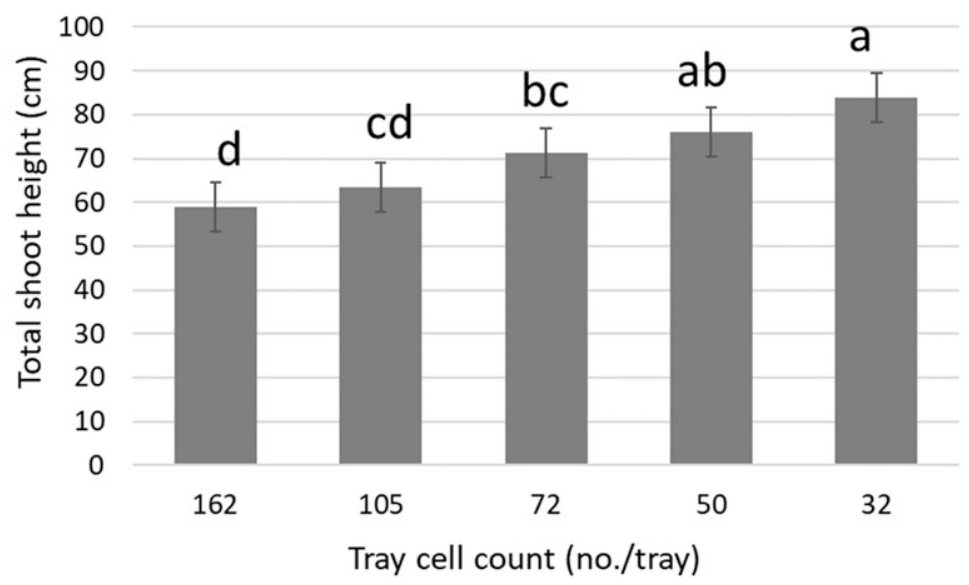

Fig. 2. Main effects of transplant seedling tray cell count on basil shoot fresh weight (A), shoot dry weight (B), and shoot height (C) per plant at harvest 35 $\mathrm{d}$ after sowing seed for the second experiment. Data represent least-square means of nine replicates per treatment. Mean separation was performed using Tukey's honestly significant difference (HSD) with $\alpha=0.05$. Error bars represent $95 \%$ confidence intervals of each mean. $1 \mathrm{~g}=0.0353 \mathrm{oz} ; 1 \mathrm{~cm}=0.3937$ inch. compared with the EC of 1.3 $\mathrm{mS} \cdot \mathrm{cm}^{-1}$ in the applied nutrient solution. In hydroponic culture, plants also received a constant supply of nutrient solution, and root systems expanded in NFT troughs for greater exposure to nutrients and water. The combination of a large root volume and early transplant to hydroponics may have resulted in less root restriction and a nearly optimal supply of nutrients and water for plant growth.

Past research with bedding plants has shown that the transplant of large seedling plugs to containers can increase production efficiency and reduce costs (Fisher, 2008; Fisher et al., 2006). In this study, transplanting basil seedlings at later dates decreased harvested shoot weights across seedling tray and root volume treatments (Fig. 1), possibly because root zone factors limited growth during seedling production, as previously discussed. Final shoot weights were also greatest for seedlings grown in the largest root volume $\left[98.1 \mathrm{~cm}^{3}(32\right.$ cell-count tray)] and transplanted at the earliest date ( $14 \mathrm{~d}$ after sowing). Therefore, results of this study did not suggest that transplanting large basil seedlings could increase spaceuse efficiency after transplant without compromising yield. However, if root zone factors could be horticulturally managed to improve basil growth during seedling production and minimize effects on final yield, then there may still be a cost-benefit to transplanting large seedling plugs in hydroponic systems. Edible crop growers would likely benefit from further investigations of maximizing plant growth during seedling production as well as evaluations of the effects of seedling size and transplant practices on spaceuse and production efficiencies.

\section{Conclusions}

Basil yield of the SAEF system was intermediate compared with yields of commercially used DWC and NFT hydroponic systems; the yield was greatest for DWC and lowest for NFT. These results suggest that ornamental bedding plant growers using ebb-and-flood irrigation can potentially modify these systems for edible crop production without having to purchase DWC and NFT hydroponic equipment. Differences in yields between culture systems may have resulted from differences in 
nutrient supply and availability for plant uptake. Increasing the substrate water-holding capacity and/or adjusting the applied nutrient concentration and fertigation frequency are potential strategies for increasing the nutrient supply and yield in the SAEF system.

Transplanting large basil seedlings to NFT hydroponic systems did not increase space-use efficiency after transplant without compromised yield. Root zone factors, particularly root volume and nutrient management practices, likely limited plant growth during seedling production and impacted the final yield in this study. Further investigations of maximizing plant growth during seedling production and evaluations of the effects of seedling size and transplant practices are needed to determine the potential for increasing space-use and production efficiencies.

\section{Literature cited}

Bar-Yosef, B. 2008. Fertigation management and crops response to solution recycling in semi-closed greenhouses, $\mathrm{p}$. 343-416. In: M. Raviv and J.H. Lieth (eds.). Soilless culture, theory and practice. Elsevier, London, UK.

Blok, C., B.E. Jackson, X. Guo, P.H. de Visser, and L.F. Marcelis. 2017. Maximum plant uptakes for water, nutrients, and oxygen are not always met by irriga- tion rate and distribution in water-based cultivation systems. Front. Plant Sci. 8:115 .

Chidiac, J. 2017. Shallow aggregate ebband-flow system for greenhouse lettuce production. MS Thesis, Univ. Arkansas, Fayetteville.

Currey, C. 2017. A systematic approach. 2 July 2020 . <https://www. producegrower.com/article/a-systematicapproach $/>$.

Fisher, P.R. 2008. What is the most profitable liner size? 2 July 2020. <https:// www.greenhousegrower.com/production/ plant-culture/the-most-profitable-linersize $>$.

Fisher, P.R., H. Warren, and L. Hydock. 2006. Larger liners, shorter crop time. 2 July 2020. <http://www.microfarms. com/technical/greenhousecd/ greenhouse/temperature/Larger Liners_Shorter_Crop_Time_by_Fisher. pdf $>$.

Gómez, C., C.J. Currey, R.W. Dickson, H.J. Kim, R. Hernández, N.C. Sabeh, R.E. Raudales, R.G. Brumfield, A. LauryShaw, A.K. Wilke, and R.G. Lopez. 2019. Controlled environment food production for urban agriculture. HortScience 54:14481458 .

Latimer, J.G. 1991. Container size and shape influence growth and landscape performance of marigold seedlings. HortScience 26:124-126.
Lieth, J.H. and L.R. Oki. 2008. Irrigation in soilless production, p. 117-144. In: M. Raviv and J.H. Lieth (eds.). Soilless culture, theory and practice. Elsevier, London, UK.

Resh, H.M. 2012. Hydroponic food production: A definitive guidebook for the advanced home gardener and the commercial hydroponic grower. CRC Press, Boca Raton, FL.

Sonneveld, C. and W. Voogt. 2009. Plant nutrition of greenhouse crops. Springer, Dordrecht, The Netherlands.

van Iersel, M. 1997. Root restriction effects on growth and development of salvia (Salvia splendens). HortScience 32:11861190.

Walters, K.J. and C.J. Currey. 2015a. Hydroponic greenhouse basil production: Comparing systems and cultivars. HortTechnology 25:645-650.

Walters, K.J. and C.J. Currey. 2015b. How to choose the right hydroponic production system for growing basil. 29 July 2020. <https://www.greenhousegrower.com/ production/how-to-choose-the-righthydroponic-production-system-for-growingbasil/ $>$.

Wolf, M.M., A. Spittler, and J. Ahern. 2005. A profile of farmer's market consumers and the perceived advantages of produce sold at farmers markets. J. Food Distrib. Res. 36:192-201. 